\title{
Bilateral Atraumatic Compartment Syndrome of the Legs Leading to Rhabdomyolysis and Acute Renal Failure Following Prolonged Kneeling in a Heroin Addict. A Case Report and Review of Relevant Literature
}

\author{
Saptarshi Biswas, Ramya S Rao, April Duckworth, Ravi Kothuru, Lucio Flores, Sunil Abrol
}

\begin{abstract}
Introduction: Compartment syndrome is defined as a symptom complex caused by increased pressure of tissue fluid in a closed osseofascial compartment which interferes with circulation to the myoneural components of the compartment. Bilateral compartment syndrome of the legs is a rare presentation requiring emergent surgical intervention. In a recent case report (Khan et al 2012) there have been only eight reported cases cited with bilateral compartment syndrome.

Heroin abuse is known to cause compartment syndrome, traumatic and atraumatic rhabdomyolysis. Hypothyroidism can also independently present with rhabdomyolysis.
\end{abstract}

Case presentation: We present a case of a 22 years old female who presented with bilateral swelling of the legs with associated loss of sensation having spent two days kneeling against the wall following IV heroin abuse. She presented to the emergency department with bilateral swelling of the legs with loss of sensation. She was diagnosed with compartment syndrome requiring emergent bilateral 4 compartment fasciotomy of the lower extremities. Inspite of aggressive fluid resuscitation she developed rhabdomyolysis complicated by acute renal failure requiring dialysis. She made a full recovery with full return of her renal as well as motor and sensory function.

Conclusion: We discuss this interesting case of bilateral compartment syndrome in a heroin abusive patient with history of hypothyroidism complicated by rhabdomyolysis and acute renal failure. There have been isolated case reports of bilateral compartment syndrome following prolonged surgery. High index of suspicion, early recognition and therapeutic intervention is the key to good outcome.We discuss the etiopathology and management options of rhabdomyolysis. Treating the comorbities like hypothyroidism is also important for the recovery.

Keywords: Bilateral, Spontaneous atraumatic compartment syndrome, Rhabdomyolysis, Acute renal failure.

How to cite this article: Biswas S, Rao RS, Duckworth A, Kothuru R, Flores L, Abrol S. Bilateral Atraumatic Compartment Syndrome of the Legs Leading to Rhabdomyolysis and Acute Renal Failure Following Prolonged Kneeling in a Heroin Addict. A Case Report and Review of Relevant Literature. J Trauma Critical Care Emerg Surg 2013;2(3):139-145.

Source of support: Nil

Conflict of interest: None

\section{RESUMEN}

Introducción: El síndrome compartimental se define como un complejo de síntomas que esta causada por el aumento de la presión de fluido del tejido en un compartimento osseofascial cerrado, que interfiere con la circulación de los componentes mioneurales del compartimento. Síndrome compartimental bilateral de las piernas es una presentación raro que requiere una intervención quirúrgica urgente. En un reporte reciente (Khan et al 2012), ha habido reportados solo 8 casos de síndrome compartimental bilateral.

Se sabe que el abuso de heroína puede causar el síndrome compartimental y rabdomiólisis traumática y atraumática. El hipotiroidismo también puede presentarse independiente con rabdomiólisis.

Presentación del caso: Presentamos un caso de una mujer de 22 años quien presentó con tumefacción bilateral de las piernas asociado con la perdida de la sensación, después de pasar dos días arrodillado contra una pared después de usar heroína intravenosa. Ella presentó al departamento de emergencias con tumefacción bilateral de las piernas con la pérdida de sensación. Ella fue diagnosticada con el síndrome compartimental que requerío una fasciotomía emergente de 4 compartimentos bilateral de las extremidades inferiores. A pesar de resucitación fluido agresivo, ella desarrolló rabdomiolisis que se complicó con insuficiencia renal aguda que requerío diálisis. Ella hizo una recuperación completa con regreso completo de su función renal, motor, y sensorio.

Conclusiones: Nosotros discutimos este caso interesante de síndrome compartimental bilateral de una paciente quien abuso heroína y tiene una historia de hipotiroidismo que estaba complicado con rabdomiolisis y insuficiencia renal aguda. Ha habido reportes aislados de síndrome compartimental bilateral después de cirugía prolongada. Alto índice de sospecha, reconocimiento temprano y intervención terapéutica son la clave para un buen resultado. Nosotros discutimos la etiopatogenia y las opciones de manejo de rabdomiolisis. Atendieno los comorbilidades como hipotiroidismo es importante también para la recuperación.

Palabras claves: Síndrome bilateral espontáneo compartimento atraumática, Rabdomiolisis, Insuficiencia renal aguda.

\section{INTRODUCTION}

Compartment syndrome is a condition in which myoneural anoxia results from a prolonged increase in tissue pressure within a closed osseofascial space. ${ }^{1}$ The result is a compromised blood flow of the skeletal muscle locally, at the microvascular level, resulting in interstitial edema and a rise in compartment pressure. Untreated it may lead to permanent neurovascular damage, myoglobinuria, renal failure, sepsis and even death. ${ }^{2}$

Common causes include open/closed fractures, crush injuries of the extremities, osteosynthesis, arterial injury, 
vascular occlusion and revascularization, burns, drug overdose and even myositis of viral etiology. ${ }^{3,4}$ It has been also been described as a complication of some positions adopted for surgery specifically lithotomy and knee chest positions. ${ }^{5}$

We report an unique case of bilateral atraumatic compartment syndrome in a heroin abusive patient with history of hypothyroidism complicated by rhabdomyolysis and acute renal failure.

High index of suspicion, early recognition and multidisciplinary therapeutic approach is the key to good outcome.

\section{CASE REPORT}

A 22 years old Caucasian female was brought in to the emergency department with the chief complaint of pain and swelling of her both lower extremities with associated loss of sensation. According to the patient she injected heroin and hid in the closet in a kneeling position with forehead resting on the wall. She fell unconscious for unknown period of time. Her roommate found her, called for the ambulance and brought her into the hospital.

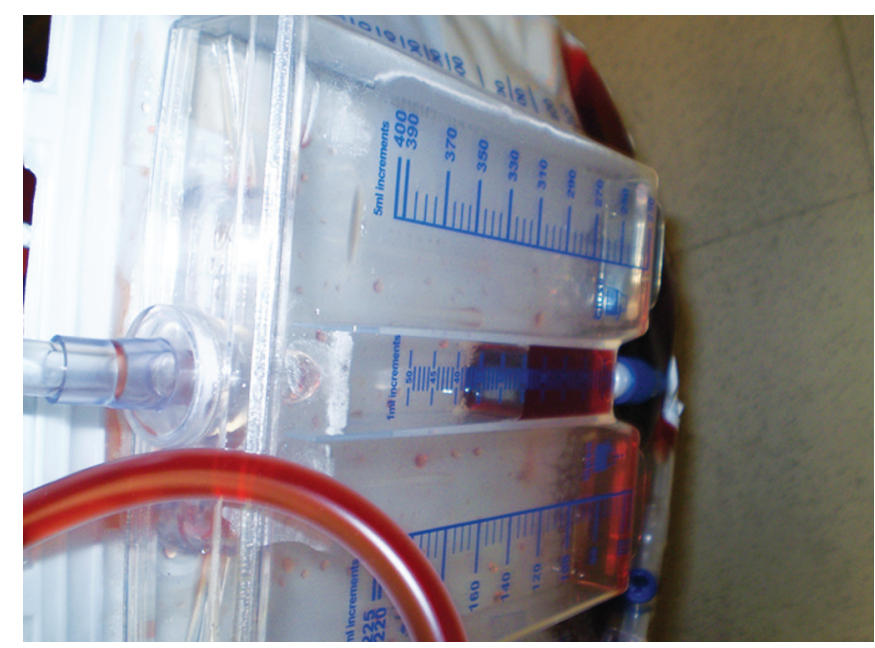

Fig. 1: Dark urine due to the presence of myoglobin

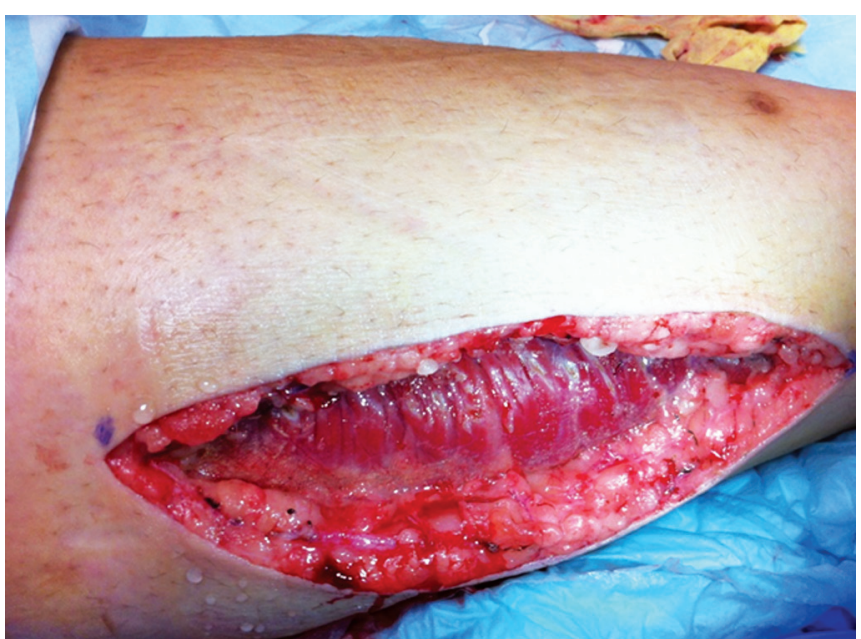

Past medical history included asthma, bipolar disorder and hypothyroidism. Patient was on thyroid hormone replacement. She smoked tobacco and marijuana, drank alcohol occasionally and injected heroin although she had a period of abstinence of 6 months before the current usage.

On physical examination she was afebrile with stable vital signs. Both lower extremities were swollen, warm and tender to palpation, edematous with petechie. There was loss of sensation of bilateral toes, right toes greater than the left. Right dorsalis pedis was palpable, but left was diminished.

Urine was red in color (Fig. 1), was positive for blood, bilirubin and leukocyte esterase but was negative for RBC. WBC was elevated at $14.8(\mathrm{~N} 4-1110 \times 9 / 1) \mathrm{D}$ dimmer 914 (N 0-278 ng/ml) BUN 40 (N 7-17 mg/dl) Creatinine 6.8 (N 0.52-1.04 mg/dl) Potassium 5.1(N 3.5-5.1 mEq/l) Phosphorus 6.7 (2.5-4.5 mg/dl) calcium 8 (N 8.4-10.2 mg/dl). AST and ALT was elevated while bilirubin was within normal limit. Creatinine kinase was elevated. The levels showed more than 160000 (N30-135 U/L) Subsequently thyroid function was done and TSH was 17.7(N0.46$4.68 \mathrm{mIU} / \mathrm{L}$ ) free thyroxine was with in normal limit.

Patient was started with aggressive intravenous hydration, Vascular surgery was consulted for evaluation of tense bilateral lower extremity. Compartment pressures were measured. Right lower extremity anterior compartment pressure was $45 \mathrm{~mm} \mathrm{Hg}$, while that on left was $51 \mathrm{~mm} \mathrm{Hg}$. Patient underwent bilateral four quadrant compartment lower extremity fasciotomy (Figs 2 and 3). With aggressive IV hydration and sodium bicarbonate infuse on creatinine kinase started trending down but patient went into acute renal failure. While BUN, creatinine was elevated with peak BUN of 109 and creatinine of 23 on day 7 of admission. During this time patient also complained of severe nausea and vomiting. Uremic gastritis was diagnosed and patient underwent dialysis twice during the hospital stay.

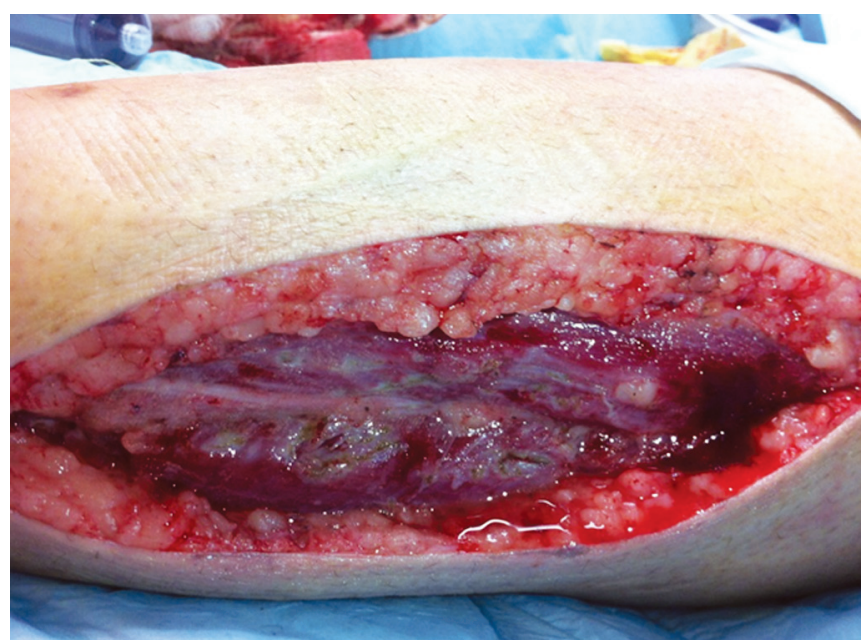

Fig. 2: Bilateral fasciotomy 
Lateral fasciotomy site of right lower extremity and medial fasciotomy site of left lower extremity were closed on hospital day 21. On day 23 of admission BUN was 18 , Creatinine 1.7 , potassium 4.8 and creatinine kinase 367 (Graphs 1 and 2). Patient was discharged home with wound VAC to the lower extremity fasciotomy sites. She was ambulating and she had return of sensation in bilateral lower extremity. Patient returned subsequently for closure of the remaining lower extremity fasciotomy wounds. She is presently being followed up in the vascular clinic and has continued to lead a normal life.

\section{DISCUSSION}

Our case describes atraumatic bilateral compartment syndrome complicated by rhabdomyolysis. Exercise is described as most common cause of bilateral atraumatic compartment syndrome ${ }^{6}$ followed by abnormal position.

Patients with alcohol ${ }^{7}$ or substance abuse, lying in abnormal position for prolonged period due to unconsciousness are predisposed to compartment syndrome.
Most of these patients are obtunded, they do not have the cognitive ability to give proper history when they present to the hospital. Also the diagnosis and the indication of operative treatment of compartment syndrome is mainly based on clinical presentation, thus often causing delay in diagnosis and treatment.

\section{ETIOPATHOGENESIS}

Lower extremity is a closed osseofascial compartment. Edema causes increased intracompartmental pressure leading to ischemia. This results in tissue membrane damage and leakage of fluid through capillary and muscle membrane. Arterial reperfusion leads to further leakage through damaged membrane and raises the hydrostatic pressure. This leads to a vicious cycle and when capillary perfusion is critically compromised muscle infarction and nerve damage occurs (Graph 3). ${ }^{4}$

Left untreated it leads to foot drop, ischemic contracture, painful paresthesia and permanent loss of function. Young
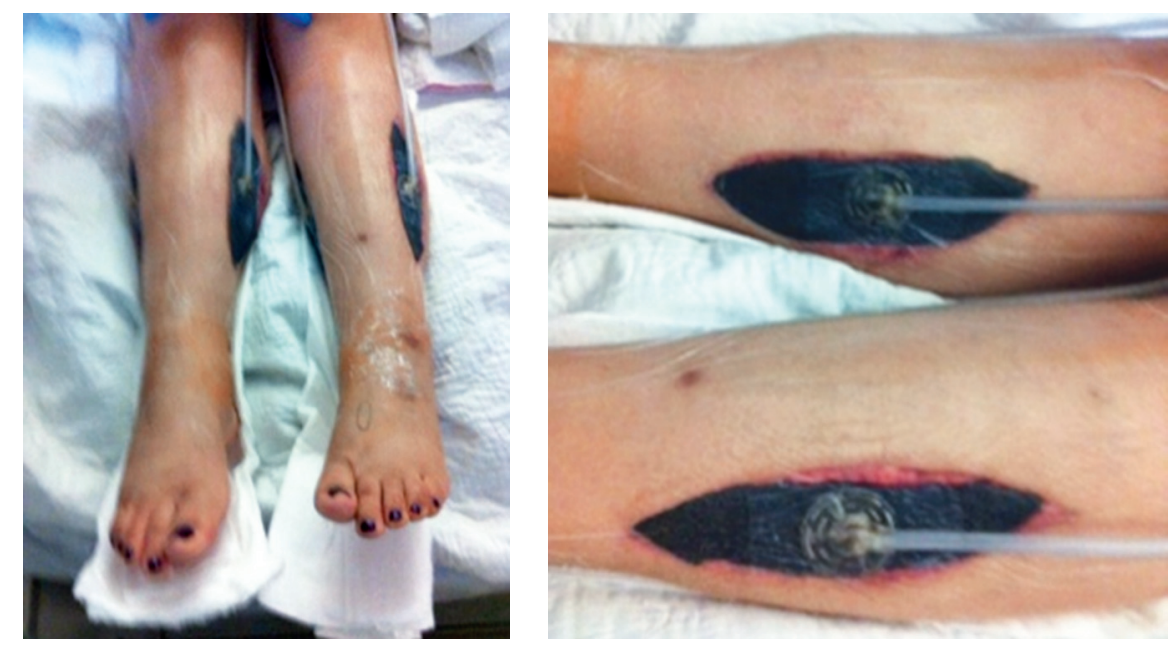

Fig. 3: Bilateral wound VAC in place postfasciotomy

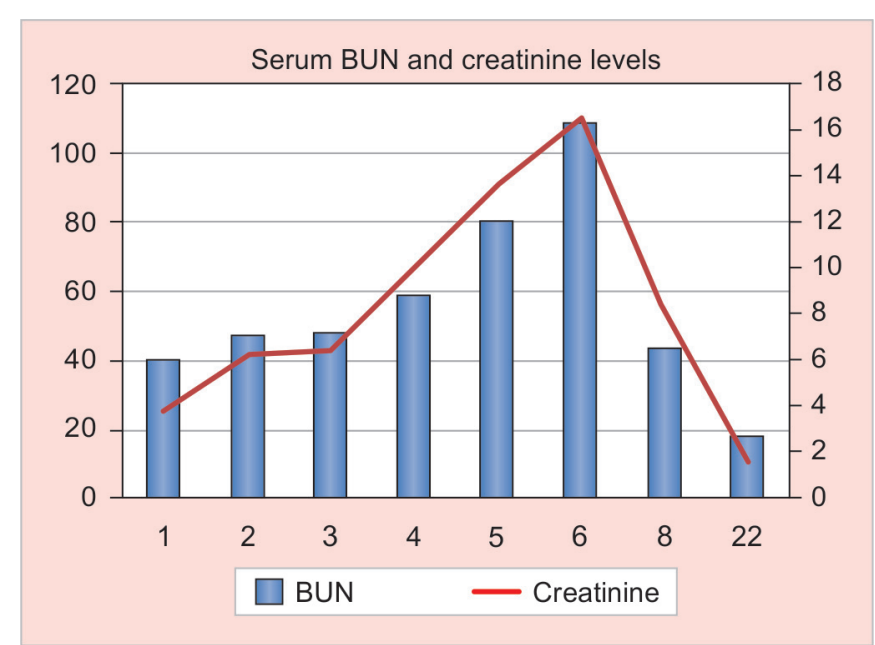

Graph 1: BUN and creatinine trend during the hospital stay

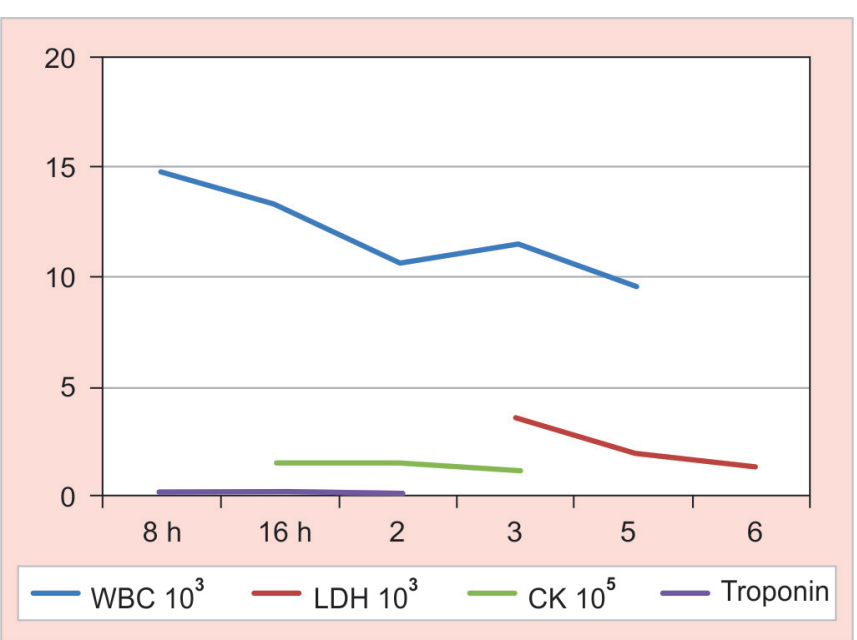

Graph 2: The course of the different markers during the hospital stay of the patient 


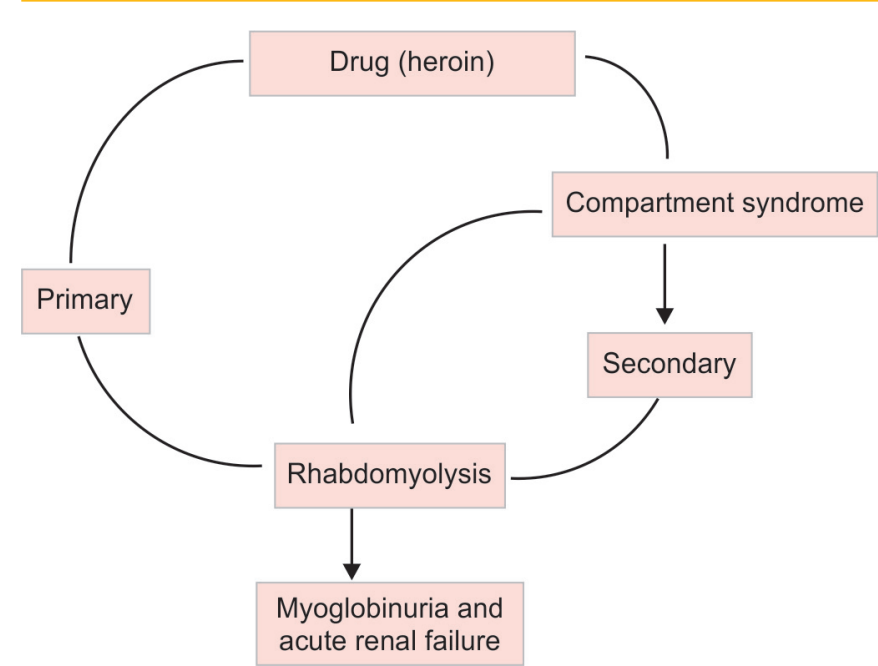

Graph 3: Pathogenesis heroin induced compartment syndrome and rhabdomyolysis

individuals are more predisposed compared to elderly because of the tight and strong fascia and the muscle mass.

Rhabdomyolysis presents with weakness, myalgia, myoglobinuria or overt renal failure. Myoglobin released from the muscle into the circulation is filtered by glomeruli causing myoglobinuria. Excessive myoglobin gets deposited in the kidney causing renal tubular obstruction and renal vasoconstriction. Associated hypovolemia, acidosis and direct cytotoxicity of myoglobin leads to acute renal failure. ${ }^{8}$

Drug-induced rhabdomyolysis can be primary due to myotoxic effect or secondary when local muscle compression occurs in coma. ${ }^{9}$

Ethanol, drugs of abuse, and statins are commonly implicated.$^{10}$ Cocaine, heroin, other opiates, amphetamines, other 'club drugs', e.g. ecstasy and benzodiazepines are known to cause rhabdomyolysis. ${ }^{11,12}$ One of the common mechanism through which all these drugs induce rhabdomyolysis is the muscle compression and ischemia, usually due to prolonged immobilization on a rigid ground, after an acute intoxication and resulting unconsciousness or coma as in our patient. ${ }^{12}$

Bilateral compartment syndrome and rhabdomyolysis has been described in various postsurgical patients who underwent surgery in lithotomy, kneeling and even supine position. ${ }^{13-15}$

Lithotomy position for more than 3 to 5 hours is known to predispose to compartment syndrome. Main reasons cited apart from decrease in arterial pressure are compression from equipment or personnel, pressure from improper placement of the leg and dorsiflexion of foot. ${ }^{16}$

Heroin is commonly used by injecting. It can also be smoked and snorted. Most illict heroin are impure, with national average purity being $36.8 \%$. The mechanism causing rhabdomyolysis in heroin a addicts notably include local compressions with muscle ischemia (prolonged immobilization), by direct myotonic effects of heroin,vasoconstriction of skeletal muscle and immunologic reaction. ${ }^{17-22,25}$

Gans JD et al presented a case series of seven patients of rhabdomyolysis in heroin addicts. No muscle compression or coma preceeding rhabdomyolysis were noted in 6 out of these 7 patients. However interestingly they also observed that five out of seven patients had period of abstinence for 3 to 12 months and there was associated nerve or plexus injury indicating role of hypersensitivity or toxicity to heroin or the impurities in causing rhabdomyolysis. ${ }^{20}$

Resumed heroin abuse after a period of abstinence has been reported in cases of rhabdomyolysis as well as with nervous system lesions. ${ }^{20,23-28}$ Our patient admitted to a period of abstinence of 6 months from heroin injection when she presented to the hospital.

Hypothyroid patients can have myopathy with mild elevation of CK levels but there are few case reports in the literature where hypothyroidism presented with rhabdomyolysis and even acute renal failure. ${ }^{29-32}$ The exact mechanism of rhabdomyolysis is hypothyroidism is unknown but impaired mitochondrial oxidative mechanism, induction of insulin resistant state and decreased muscle creatinine levels has been hypothesized.

Drugs and abnormal position, and hypothyroidism can cause rhabdomyolysis with or without compartment syndrome. Exercise and hydration status and medical comorbidities affect both condition.

\section{DIAGNOSIS}

Clinical features of compartment syndrome are classically described as pain, pallor, paresthesia, paralysis and pulselessness which is usually a late sign. Obtaining a history of pain and paresthesia from an obtunded patient may be difficult. Absence of clinical finding is useful in excluding the diagnosis of compartment syndrome. The resting intra compartmental pressure ranges from 0 to $8 \mathrm{~mm} \mathrm{Hg}$. When the pressure reaches 20 to $30 \mathrm{~mm} \mathrm{Hg}$ clinical features start to appear. There are commercially available pressure monitors which can be used to measure compartment pressure. Large bore catheter connected to pressure monitor through IV tubing filled with saline solution can be used as a substitute.

Shadgan B et $\mathrm{al}^{4}$ describe in their review about inflammatory biomarkers like WBC, ESR, CK, Myoglobin, troponin I and fatty acid binding proteins in acute compartment syndrome. In our case when the patient presented to the hospital there was a mild elevation of WBC and troponin I, marked elevation of myoglobin, creatinine kinase and LDH. In atraumatic etiology of compartment syndrome like ours, these inflammatory markers could be useful aid in the diagnosis. 
Near infrared spectroscopy can prove to be a very useful technique for continuous monitoring in acute compartment syndrome. It detects local muscle oxygenation and perfusion by using optical activity of oxy and deoxy hemoglobin. Other newer techniques for the monitoring of compartment pressure include ultrafiltration catheters and radiofrequency identification implants. ${ }^{33}$

When rhabdomyolysis leads to myoglobinuria urine dipstick is positive for blood but there is no $\mathrm{RBC}$ in the urine. Lysis of myocyte also release creatine kinase and $\mathrm{LDH}^{34}$ Serum CK is elevated more than five times the upper limit in rhabdomyolysis.

$\mathrm{CK}$ levels are the most sensitive indicators of myocyte injury. The normal CK levels are between 45-260U/L. CK levels peak within 1 to 3 days, with a t-1/2 of 1.5 days. Risk of acute kidney injury increases when peak CK level is $>5000 \mathrm{U} / \mathrm{L}$ : CK comprises of three isoenzymes-CK-MM (muscles), CK-MB (heart) and CK-BB (brain and kidneys). Although rhabdomyolysis causes extreme CK elevation ${ }^{12,35,36}$ in cases of problems with differentials all of the three isoenzymes should be taken into account.

Rhabdomyolysis is also associated with other electrolyte abnormalities like hyperkalemia, hypocalcemia (when calcium gets deposited in the injured muscles as calcium phosphate), hypercalcemia (when these calcium is released from the muscle and hyperurecemia). ${ }^{37}$

Carbonic anhydrase III although the most specific for muscle injury is usually not measured because it is expensive and not easily done. Aldolase, lactic dehydrogenase and transaminases are also often elevated. Uric acid is also found to be elevated. Hypoalbuminamia, anemia, thrombocytopenia, leukocytosis and disturbances in coagulation profile are often noted. The serum anion gap is significantly higher than normal values $(12 \pm 2)$. ABG often shows hypoxia and metabolic acidosis. ${ }^{12,38}$

Acute tubular necrosis is associated with dark brown granular cast in urine. ${ }^{37}$ Urinalysis shows albumin, uric acid crystals, myoglobin besides brown casts (Ref Efstratiadis G). Myoglobin in normal healthy subjects are less than $5 \mathrm{ng} / \mathrm{ml}$. In cases where of myoglobin $>25 \mathrm{ng} / \mathrm{ml}$ urine usually gets a dark brown color. In patients with prerenal azotemia the $\mathrm{FeNa}$ is $<1 \%$. In rhabdomyolysis it is $>1 \%$. Urine toxicology screen should be done in suspected intoxications. ${ }^{12,39}$

\section{TREATMENT}

Early diagnosis followed by prompt intervention is of paramount importance for treating rhabdomyolysis.

When acute compartment syndrome is suspected all the circumferential or compressive dressing should be released and the limb should be elevated above the level of heart.
Aggressive hydration with IV fluids is important for preserving renal function. Mannitol and bicarbonate can be administered. Mannitol acts as diuretic and protects the kidney by reducing myoglobin deposition, while bicarbonate increase the PH of urine and help to solubilize myoglobin. ${ }^{8}$ Mannitol also enhances renal blood flow also the glomerular pressure. It is also have some antioxidant properties. Bicarbonate correct the urine alkanization and beneficial at correcting metabolic acidosis, myoglobin washout and the reduction in cast formation which is induced by acidic conditions. The alkanization of urine also acts to prevent renal vasoconstriction and also lipid peroxidation caused by myoglobin. ${ }^{12,40}$

Study done by Brown et al concluded that mannitol and bicarbonate do not show any benefit in patients with initial CK level $>5000$ units. $^{41}$

Compartment pressure of 30 to $45 \mathrm{~mm} \mathrm{Hg}$ correlated with clinical findings is an indication for prompt fasciotomy. There are 4 compartments in the lower extremity. Usually single compartment pressure is measured at one time. Difference between diastolic pressure and ICP (Intra compartmental pressure) or difference between MAP and ICP with a pressure difference $\leq 30$ is the threshold for fasciotomy. ${ }^{42}$

Electrolyte abnormalities in these patients can lead to cardiac dysrhythmias. Due to the hypercalcemia in the recovery phase in 20 to $30 \%$ of the patients calcium gluconate is administered with caution in these patients and reserved for patients with severe hyperkalemia or symptomatic hypocalcemia. ${ }^{37}$

Indication for dialysis in these patients would be refractory hyperkalemia, acidosis or uremic symptoms. Our patient presented with excessive nausea and vomiting during the early part of the hospital course besides progressively worsening renal dysfunction. With raising potassium, BUN and creatinine levels, uremic gastritis was suspected and the patient underwent dialysis twice during the hospital stay.

Rice et $\mathrm{al}^{43}$ a studied the incidence of renal failure due to heroin-related rhabdomyolysis. They indicated high admission CK and creatinine levels, high peak CK level and a low urine output in initial 24 hours as the predisposing factors for requirement of dialysis in these patients. Our patient required dialysis and had an admission CK of 120821 $\mathrm{U} / \mathrm{L}$ peak CK of $50383 \mathrm{U} / \mathrm{L}$ and creatinine 6.2 and low UOP in first 24 hours consistent with the result of their study.

Kisakol et $\mathrm{al}^{44}$ presented a case of a young male with rhabdomyolysis in a hypothyroid patient. He recovered with levothyroxine replacement with improvement in muscle function over 8 weeks and normalization of serum creatine kinase in 12 weeks. 
Altay et $\mathrm{al}^{30}$ presented a case of rhabdomyolysis and ARF in an elderly diabetic who was hypothyroid while Macleod et al published a similar case of rhabdomyolysis and ARF in a hypothyroid patient. Both recovered with levothyroxine treatment. The replacement dosage varied from 100 to $150 \mu \mathrm{g}$ of $\mathrm{L}$ thyroxine. Our patient also received levothyroxine with slow increment to $75 \mu \mathrm{g}$. Treatment of comorbidities like hypothyroidism is important in recovery of these patients.

\section{CONCLUSION}

This was an interesting case of bilateral atraumatic compartment syndrome in a heroin abusive patient with history of asthma and hypothyroidism complicated by rhabdomyolysis and acute renal failure. Early recognition and aggressive management of this condition is crucial. Fasciotomy for compartment syndrome, IV hydration and monitoring creatinine kinase and electrolytes, dialysis when indicated for acute renal failure and care of the fasciotomy wound are the mainstay of treatment. Identifying and treating the comorbities like hypothyroidism is also important for the recovery.

\section{REFERENCES}

1. Mubarak SJ, Owen CA, Hargens AR, Garetto LP, Akeson WH. Acute compartment syndromes: diagnosis and treatment with the aid of the wick catheter. J Bone Joint Surg Am 1978 Dec; 60(8):1091-1095.

2. Mulhall JP, Drezner AD. Postoperative compartment syndrome and the lithotomy position: a report of three cases and analysis of potential risk factors. Conn Med 1993 Mar;57(3):129-133.

3. Khan T, Lee GH, Alvand A, Mahaluxmivala JS. Spontaneous bilateral compartment syndrome of the legs: a case report and review of the literature. Int J Surg Case Rep 2012;3(6):209-211.

4. Shadgan B, Menon M, Sanders D, Berry G, Martin C Jr, Duffy P, Stephen D, O’Brien PJ. Current thinking about acute compartment syndrome of the lower extremity. Can J Surg 2010 Oct;53(5):329-334.

5. Aschoff A, Steiner-Milz H, Steiner HH. Lower limb compartment syndrome following lumbar discectomy in the knee-chest position. Neurosurg Rev 1990;13(2):155-159.

6. Boland MR, Heck C. Acute exercise-induced bilateral thigh compartment syndrome. Orthopedics 2009 Mar;32(3):218.

7. Sofat N, Bell S, Turner J, Warrens AN. A case of acute renal failure and compartment syndrome after an alcoholic binge. J Accid Emerg Med 1999 Jul;16(4):296-298.

8. Boutaud O, Roberts LJ 2nd. Mechanism-based therapeutic approaches to rhabdomyolysis-induced renal failure. Free Radic Biol Med 2011 Sep 1;51(5):1062-1067. Epub 2010 Oct 27.

9. Coco TJ, Klasner AE. Drug-induced rhabdomyolysis. Curr Opin Pediatr 2004 Apr;16(2):206-210.

10. Warren JD, Blumbergs PC, Thompson PD. Rhabdomyolysis: a review. Muscle Nerve 2002;25:332-347.

11. Efstratiadis G, Voulgaridou A, Nikiforou D, Kyventidis A, Kourkouni E, Vergoulas G. Rhabdomyolysis updated. Hippokratia 2007 Jul-Sep;11(3):129-137.
12. Criddle L. Rhabdomyoysis. Pathophysiology, recognision and management. Critical Care Nurse 2003;23:14-32.

13. Chin KY, Hemington-Gorse SJ, Darcy CM. Bilateral well leg compartment syndrome associated with lithotomy (Lloyd Davies) position during gastrointestinal surgery: a case report and review of literature. Eplasty 2009 Oct 14;9:e48.

14. Turnbull D, Mills GH. Compartment syndrome associated with the Lloyd Davies position. Three case reports and review of the literature. Anaesthesia 2001 Oct;56(10):980-987.

15. Kavouni A, Ion L. Bilateral well-leg compartment syndrome after supine position surgery. Ann Plast Surg 2000 Apr;44(4):462-463.

16. Tuckey J. Bilateral compartment syndrome complicating prolonged lithotomy position. Br J Anaesth 1996 Oct;77(4): 546-549.

17. Madhusoodanan S, Gupta S, Calleja G, Bogunovic O, Brenner R. A case of rhabdomyolysis after intravenous heroin use. Prim Care Companion J Clin Psychiatry 2004;6(5):221-222.

18. Chan YF, Wong PK, Chow TC. Acute myoglobinuria as a fatal complication of heroin addiction. Am J Forensic Med Pathol 1990;11:160-164.

19. Schwartzfarb L, Sing G, Marcus D. Heroin associated rhabdomyolysis with cardiac involvement. Arch Intern Med 1977;137:1255-1257.

20. De Gans J, Stam J, Van Wijngaarden GK. Rhabdomyolysis and concomitant neurological lesions after intravenous heroin abuse. J Neurol Neurosurg Psychiatry 1985;48:1057-1059.

21. Koppel C. Clinical features, pathogenesis and management of drug induced rhabdomyolysis. Med Toxicol Adverse Drug Exp 1989;4:108-126.

22. Jacome DE. Neurogenic bladder, lumbosacral plexus neuropathy and drug associated rhabdomyolysis [letter] J Urol 1982;127:994-995.

23. Richter RW, Challenor YB, Pearson J, Kagen LJ, Hamilton LL, Ramsey WH. Acute myoglobinuria associated with heroin addiction. JAMA 1971 May 17;216(7):1172-1176.

24. Richter RW, Pearson J, Bruun B, Challenor YB, Brust JC, Baden MM. Neurological complications of addiction to heroin. Bull N Y Acad Med 1973 Jan;49(1):3-21.

25. Challenor YB, Richter RW, Bruun B, Pearson J. Nontraumatic plexitis and heroin addiction. JAMA 1973 Aug 20;225(8): 958-961.

26. Greenwood RJ. Lumbar plexitis and rhabdomyolysis following abuse of heroin. Postgrad Med J 1974 Dec;50(590):772-773.

27. Loizou LA, Boddie HG. Polyradiculoneuropathy associated with heroin abuse. J Neurol Neurosurg Psychiatry 1978 Sep;41(9):855-857.

28. Richter RW, Baden MM. Neurological complications of heroin addiction. Trans Am Neurol Assoc 1969;94:330-332.

29. Comak E, Koyun M, Kiliçarslan-Akkaya B, Bircan I, Akman S. Severe rhabdomyolysis and acute renal failure in an adolescent with hypothyroidism. Turk J Pediatr 2011 SepOct;53(5):586-589.

30. Altay M, Duranay M, Ceri M. Rhabdomyolysis due to hypothyroidism. Nephrol Dial Transplant 2005;20:847-848.

31. Kar PM, Hirani A, Allen MJ. Acute renal failure in a hypothyroid patient with rhabdomyolysis. Clin Nephrol 2003;60:428-429.

32. Barahona JM, Mauri A, Sucunza N, et al. Hypothyroidism as a cause of rhabdomyolysis. Endocr J 2002;49:621-623.

33. Harvey EJ, Sanders DW, Shuler MS, Lawendy AR, Cole $\mathrm{AL}$, Alqahtani SM, et al. What's new in acute compartment syndrome? J Orthop Trauma 2012 Dec;26(12):699-702. 
34. Daher Ede F, Silva Júnior GB, Brunetta DM, Pontes LB, Bezerra GP. Rhabdomyolysis and acute renal failure after strenuous exercise and alcohol abuse: case report and literature review. Sao Paulo Med J 2005 Jan 2;123(1):33-37. Epub 2005 Mar 31.

35. Criddle L. Rhabdomyoysis. Pathophysiology, recognision and management. Critical Care Nurse 2003;23:14-32.

36. Russell T. Acute renal failure related to rhabdomyolysis: pathophysiology, diagnosis and collaborative management. Nephr Nurs J 2005;32:409-417.

37. Huerta-Alardín AL, Varon J, Marik PE. Bench-to bedside review: Rhabdomyolysis: an overview for clinicians. Crit Care 2005 Apr;9(2):158-169. Epub 2004 Oct 20.

38. Haskins N. Rhabdomyolysis and acute renal failure in intensive care. Nurs Crit Care 1998;3:283-288.

39. David WS. Myoglobinuria. Neurol Clin 2000;18:215-243.

40. Holt SG, Moore KP. Pathogenesis and treatment of renal dysfunction in rhabdomyolysis. Intensive Care Med 2001; 27:803-811.

41. Brown C, Rhee P, Chan L, Evans K, Demetriad s D, Velmahos G. Preventing renal failure in patients with rhabdomyolysis: Do Bicarbonate and Mannitol Make a Difference? J Trauma 2004;56:1191-1196.

42. Erdös J, Dlaska C, Szatmary P, Humenberger M, Vécsei V, Hajdu S. Acute compartment syndrome in children: a case series in 24 patients and review of the literature. Int Orthop 2011 Apr;35(4):569-575.

43. Rice EK, Isbel NM, Becker GJ, Atkins RC, McMahon LP. Heroin overdose and myoglobinuric acute renal failure. Clin Nephrol 2000 Dec;54(6):449-454.

44. Kisakol G, Tunc R, Kaya A. Rhabdomyolysis in a patient with hypothyroidism. Endocr J 2003 Apr;50(2):221-223.

\section{ABOUT THE AUTHORS}

\section{Saptarshi Biswas (Corresponding Author)}

Resident, Department of General Surgery, Brookdale University Hospital Medical Center, Brooklyn, NY, USA, e-mail: saptarshibiswas@ comcast.net

\section{Ramya S Rao}

Resident, Department of Surgery, Brookdale University Hospital Medical Center, Brooklyn, NY, USA

\section{April Duckworth}

Resident, Department of Surgery, Brookdale University Hospital Medical Center, Brooklyn, NY, USA

\section{Ravi Kothuru}

Program Director, Director of Thoracic Surgery, Department of General Surgery, Brookdale University Hospital Medical Center Brooklyn, NY, USA

\section{Lucio Flores}

Director of Vascular Surgery and Associate Chairman, Department of General Surgery, Brookdale University Hospital Medical Center Brooklyn, NY, USA

\section{Sunil Abrol}

Chairman, Department of General Surgery, Brookdale University Hospital Medical Center, Brooklyn, NY, USA 